\title{
TEORIA DA DUPLA IMPUTAÇÃO: CONDIÇÃO DE PROCEDIBILIDADE DA AÇÃO PENAL E OS CRIMES AMBIENTAIS
}

\author{
Felipe Braga de Oliveira ${ }^{1}$ \\ Luciana de Souza Breves ${ }^{2}$
}

\begin{abstract}
RESUMO
O presente artigo tem como escopo analisar as perspectivas doutrinárias quanto à condição de procedibilidade da ação penal em crimes ambientais quando o agente causador do dano for uma personalidade jurídica. Abordaremos tema polêmico com vistas à Teoria da Dupla Imputação, fazendo análise cronológica das interpretações legais sucedidas pelos Tribunais Superiores acerca da responsabilidade penal de pessoas jurídicas na prática de crimes ambientais, apresentando as divergências identificadas entre julgados. Realizou-se para tanto pesquisas bibliográficas e jurisprudenciais, sobretudo de precedentes do Superior Tribunal de Justiça, para abordagem da diversidade de críticas acerca do tema, apresentando o atual entendimento do Tribunal Cidadão quanto ao tema.
\end{abstract}

Palavras-Chave: Direito Ambiental Penal; Crimes Ambientais; Responsabilidade Penal; Pessoa Jurídica; Teoria da Dupla Imputação.

\section{DOUBLE IMPUTATION THEORY: CONDITION OF PROCEDIBILITY OF CRIMINAL ACTION AND ENVIRONMENTAL CRIMES}

\begin{abstract}
The purpose of this article is to analyze the doctrinal perspectives as to the condition for the prosecution of criminal proceedings in environmental crimes when the agent causing the damage to a legal entity. We will address a controversial issue with a view to the Double Imputation Theory, making a chronological analysis of the legal interpretations followed by the Superior Courts about the criminal liability of legal entities in the practice of environmental crimes, applying as differences between judges. For this purpose, bibliographic and jurisprudential research was carried out, above all of precedents of the Superior Court of Justice, to address the diversity of related criticisms of the theme, changing the current understanding of the Citizen Court regarding the theme.
\end{abstract}

Keywords: Criminal Evironmental Law; Environmental Crime; Criminal

\footnotetext{
${ }^{1}$ Bacharel em Direito pelo Centro Universitário do Norte (UNINORTE) e Licenciado em História pela Universidade Federal do Amazonas (UFAM). Doutorando em Direito pela Faculdade Autônoma de Direito (FADISP). Mestre em Direito Ambiental pela Universidade do Estado do Amazonas (UEA). Especialista em Direito Penal e Criminologia pela Pontifícia Universidade Católica do Rio Grande do Sul (PUCRS), em Ciências Criminais pela Pontifícia Universidade Católica de Minas Gerais (PUCMINAS), em Direito Penal e Processual Penal pela Universidade Cândido Mendes (UCAM/RJ) e em Direito Público pelo Centro Universitário do Norte (UNINORTE). Professor. Advogado. (felipe@ vilaebraga.adv.br)

${ }^{2}$ Graduada em Direito pelo Centro Universitário de Ensino Superior do Amazonas - CIESA. Mestranda em Direito Ambiental pela Universidade do Estado do Amazonas (UEA). Pós-graduada em Direito Ambiental e Sustentabilidade pela Universidade Cândido Mendes - UCAM (2016). Servidora Pública Municipal. Advogada. (lucianabrevess@hotmail.com)
} 
Responsibility; Legal Person; Double Imputation Theory.

\section{INTRODUÇÃO}

O problema com a degradação ambiental vem se evoluindo ilimitadamente, afetando todas as classes sociais e extremos territoriais a níveis nacionais e internacionais. Ocorre que no Brasil, apesar de possuir uma incomparável biodiversidade de flora e fauna, a preocupação política e social com a questão ambientalista adveio de forma retardatária.

Isso porque a primeira lei que criminalizou as práticas ilegais de degradação ambiental, a qual regulamentou o artigo $225, \S 3^{\circ}$, da Constituição Federal da República, se deu apenas em 1998, com a edição da Lei de Crimes Ambientais n. ${ }^{\circ}$ 9.605/98, a qual tipificou condutas voltadas para o Direito Ambiental Penal e definiu sanções inclusive para Pessoas Jurídicas.

Foi aí que a doutrina dividiu-se e entrou em confronto de entendimentos, tudo em relação à possibilidade, ou não, da persecução de ação penal pela prática de crimes ambientais quando estes forem cometidos por personalidades jurídicas.

À exemplo dos doutrinadores, os Tribunais Superiores também passaram a se deparar com uma vasta demanda processual em que as partes discutiam entre si a viabilidade de uma pessoa jurídica figurar no pólo passivo de uma ação penal de forma isolada.

Nesse diapasão, abordar-se-á, neste artigo, a acirrada discussão relativa à possibilidade de aplicar-se sanções penais à pessoas com personalidade de natureza jurídica quando estas atentarem criminalmente contra o equilíbrio ecológico, em condutas tipificadas na legislação especial penal.

Dessa forma, tem-se como desígnio principal deste estudo a apresentação das teorias existentes acerca da discussão mencionada, demonstrando, ao final, qual destas tem sido adotada na prática pelo Poder Judiciário.

Para alcançar os objetivos propostos, utilizou-se como recurso metodológico a pesquisa bibliográfica, realizada a partir da análise de correntes doutrinárias que divergem quanto à problemática apresentada, além de emendas de acórdãos que julgaram e criaram precedentes sobre o tema. 


\title{
2 PERSPECTIVAS DOUTRINÁRIAS
}

A Constituição Federal de 1988 já previa em seu art. 225, § $3^{\circ}$ sobre a possibilidade de responsabilização de pessoas jurídicas causadoras de dano ambiental:

\begin{abstract}
Art. 225. Todos têm direito ao meio ambiente ecologicamente equilibrado, bem de uso comum do povo e essencial à sadia qualidade de vida, impondose ao Poder Público e à coletividade o dever de defendê-lo e preservá-lo para as presentes e futuras gerações.

(...)

$\S 3^{\circ}$ As condutas e atividades consideradas lesivas ao meio ambiente sujeitarão os infratores, pessoas físicas ou jurídicas, a sanções penais e administrativas, independentemente da obrigação de reparar os danos causados. (grifo nosso)
\end{abstract}

No entanto, a Magna Carta não disciplinou em que termos se daria essa responsabilização, deixando essa tarefa para a legislação infraconstitucional.

Apenas dez anos após a promulgação da Constituição Federal de 1988 é que sobreveio a Lei $\mathrm{n}^{\circ} 9.605 / 1998$, a qual passou a criminalizar condutas e atividades lesivas ao meio ambiente e dispor sobre as sanções penais e administrativas aplicáveis aos delitos tipificados como crime ambiental, inclusive quando cometidos por pessoa jurídica.

Ocorre que mesmo depois da Lei $\mathrm{n}^{\circ}$ 9.605/98 determinar claramente a responsabilidade administrativa, civil e penal das pessoas jurídicas quando elas causarem danos ambientais surgiram algumas teorias na doutrina, em uma tentativa de compreender a amplitude dessa responsabilização.

O embate sobre a responsabilização penal, ou não, das pessoas jurídicas passou a concentrar-se em duas correntes que divergem sobre a existência da personalidade coletiva: a Teoria da Realidade e a Teoria da Ficção, as quais esmiuçaremos a seguir.

\subsection{Corrente favorável à responsabilização penal de pessoas jurídicas pela prática de crimes ambientais}

A primeira corrente, seguida por Abel Costa de Oliveira, Vladimir e Passos de Freitas, dentre outros, defendem a essência da personalidade jurídica sob o prisma da Teoria da Realidade.

Estes acreditam que as pessoas jurídicas possuem poder de deliberação e vontade distintas dos seres humanos, chamados juridicamente de pessoas físicas, podendo assim 
dirigir suas atividades para práticas delituosas, e, portanto, devendo ser responsabilizadas penalmente por isto.

Nessa linha de raciocínio, acreditam estes pensadores na existência real da pessoa jurídica, por considerarem presentes todas as características inerentes ao ser que possui personalidade, vontade própria, direitos e deveres, que no mais, são distintos das pessoas físicas que a compõem.

Nesse sentido, explica Sheila Jorge Selim Sales, verbis:

A oposta teoria da realidade sustenta que as pessoas jurídicas são seres reais, reconhecidos e regulados pela lei, possuindo potencialidade para serem sujeitos ativos de condutas puníveis, uma vez consideradas como portadoras de vontade real. (SALES, 2013, p. 223)

Assim, para esta corrente positiva há possibilidade de responsabilização penal ambiental das pessoas jurídicas, uma vez que a personalidade das pessoas coletivas não só existe por meio de técnica jurídica, mas sim através de sua existência e atuação própria e independente dentro do meio social, as quais não se confundem com a personalidade individual dos seus membros e dirigentes.

Reforçando esse entendimento Nicolao Dino; Ney de Barros e Flávio Dino, assim complementam a tese, ipsis litteris:

O princípio da pessoalidade da pena está previsto no art. $5^{\circ}$, inciso XLV e quer dizer que nenhuma pena passará da pessoa do condenado, e que ninguém será responsabilizado criminalmente por ato de outrem.Ora, quando um preposto, administrador ou sócio de uma empresa praticam ato típico, e a responsabilidade por esse ato é sustentada pela empresa, não há ruptura do pressuposto constitucional causado pela comprovação de que o ato, em verdade, era ato da própria empresa, apenas praticado por intermédio de um seu representante. $\mathrm{O}$ ato criminoso, na verdade, não é ato da pessoa física, mas sim

ato da própria pessoa jurídica que se corporifica por meio de um dos seus dirigentes, empregados, sócios ou prepostos.

$\mathrm{O}$ ato não é da pessoa física e a responsabilidade sustentada pela pessoa jurídica, mas sim ato do ente moral sustentado por ele próprio. (NETO e outros, 2011, p. 56)

Nesse caso, ressaltam que não há que se falar em violação do princípio constitucional previsto no artigo $5^{\circ}$, inciso XLV, da $\mathrm{CF} / 88$ pois é incontestável a existência de duas pessoas distintas: uma física (pessoa natural que compõe a empresa, seja membro ou dirigentes) e uma jurídica (personalidade "fictícia" criada por meio de CNPJ para atuar legalmente no meio 
social), devendo cada uma ser responsabilizada individualmente, de acordo com sua conduta lesiva.

Shecaira questiona nesse sentido:

Não seria uma burla de etiquetas permitir a reprovação administrativa e civil por um crime ecológico (por exemplo), mas não uma reprovação penal? (SHECAIRA, 1998, p.67)

Ademais, José Afonso da Silva, Pinto Ferreira e Walter Claudius Rothenburg partilham da mesma linha de raciocínio, ao defenderem a possibilidade de denunciar pessoas jurídicas, independe das pessoas de seus dirigentes, e sujeita-los às sanções compatíveis com sua natureza, pela prática de atos de degradação ambiental.

\subsection{Corrente Contrária à Responsabilização Penal de Pessoas Jurídicas Pela Prática de Crimes Ambientais}

Em contrapartida, uma segunda corrente, defendida por Zaffaroni e Pierangeli, acredita que, com base na Teoria da Ficção, a pessoa jurídica seria meramente um ente fictício formado pela vontade dos seres humanos, não podendo-lhe ser atribuída sua existência real.

Dessa forma, não teriam entes vontade autônoma tampouco capacidade volitiva, nada mais sendo do que uma reunião de seres humanos - pessoas físicas - para desenvolverem um objetivo comum, sendo considerados como um devaneio da vontade humana, o que o impossibilitariam de figurar no pólo passivo de uma eventual ação penal.

Cezar Roberto Bitencourt, em uma das suas renomadas obras, atribui uma condição limitada à responsabilidade penal em relação à responsabilidade subjetiva e individual. E, fazendo alusão à obra de René Ariel Dotti, enfatiza:

No sistema jurídico positivo brasileiro a responsabilidade penal é atribuída, exclusivamente, às pessoas físicas. Os crimes ou delitos e as contravenções não podem ser praticados pelas pessoas jurídicas, posto que a imputabilidade jurídico-penal é uma qualidade inerente aos seres humanos. (BITENCOURT, 1997, p. 228)

Ressaltam, por fim, os seguidores desta corrente, que uma vez que os entes morais não têm vontade própria, manifestando-se apenas através de seus dirigentes, seria impossível a sua responsabilização criminal dada a inviabilidade de incidência de penas sobre aqueles, 
além de considerarem o ordenamento jurídico brasileiro despreparado para a implantação da responsabilidade penal dessas personalidades coletivas.

Por isso utiliza-se tal corrente do antigo brocardo latino "societas delinquere nom potest" (SAVIGNY), que define a pessoa jurídica como ente fictício formado pela vontade de seres humanos seria irreal ao ponto de ser insuficiente como sujeito ativo na prática de um crime, portanto incapaz no sentido do Direito penal.

Nesse sentido, Sheila Jorge Selim Sales, uma das seguidoras dessa, assim salienta:

Para tal teoria, as pessoas jurídicas são entidades fictícias, criadas pelo Direito, não possuindo consciência e vontades próprias, isto é, as condições psíquicas de determinar o "querer". Não possuem, portanto, capacidade de ação e, consequentemente, não são passíveis de punição na esfera penal, uma vez ausentes os pressupostos sobre os quais se assenta o moderno Direito Penal da culpa. (SALES, 2013, p. 222)

Conclui, portanto, este entendimento doutrinário, que a adoção da responsabilidade penal à pessoas jurídicas constituiria expressa ofensa à teoria do crime, em especial na caracterização da culpabilidade; imputabilidade e tipicidade.

\section{REPERCUSSÃO NO ÂMBITO DO PODER JUDICIÁRIO}

Consoante explanado alhures, não existe consenso doutrinário acerca da possibilidade de responsabilização penal das personalidades jurídicas.

A posição jurisprudencial por sua vez, passou anos residindo idêntica divergência encontrada na doutrina, mas parece ter encontrado concordância plena e pacífica entre os julgados do Superior Tribunal de Justiça e do Supremo Tribunal Federal, nos últimos anos.

Nesse dilema se encontram o estudo cronológico do entendimento jurisprudencial das altas cortes brasileiras.

\subsection{Entendimento dos Tribunais Superiores}

Desde a criação da Lei de Crimes Ambientais foi, como visto, levantada a questão da responsabilidade penal de empresas, ante aos divergentes entendimentos quanto a essência da personalidade jurídica dessas.

Foi possível, desde então, verificar ampla divergência entre as Turmas Julgadoras dos Tribunais Superiores Brasileiros, e, muitas vezes, dentro de um mesmo Tribunal. 
Nesse dilema encontram-se os julgados do Superior Tribunal de Justiça, que podem ser citados in verbis para ilustrar a acepção dos Egrégios Tribunais sobre a punibilidade de pessoas jurídicas do Direito Ambiental Penal. Façamos análise.

Entre os ministros do Superior Tribunal sempre foi pacífico o entendimento de se reconhecer a responsabilidade penal dos entes coletivos em caso de crimes ambientais, e, consequentemente, a possibilidade de configurarem estes no pólo passivo de ações penais.

PROCESSUAL PENAL. RECURSO ESPECIAL. CRIMES CONTRA O MEIO AMBIENTE. DENÚNCIA REJEITADA PELO E. TRIBUNAL A QUO. SISTEMA OU TEORIA DA DUPLA IMPUTAÇÃO.

Admite-se a responsabilidade penal da pessoa jurídica em crimes ambientais desde que haja a imputação simultânea do ente moral e da pessoa física que atua em seu nome ou em seu benefício, uma vez que "não se pode compreender a responsabilização do ente moral dissociada da atuação de uma pessoa física, que age com elemento subjetivo próprio" cf. Resp $^{\circ}$ 564960/SC, $5^{\text {a }}$ Turma, Rel. Ministro Gilson Dipp, DJ de 13/06/2005 (Precedentes).

Recurso especial provido.

(REsp 889528 / SC RECURSO ESPECIAL 2006/0200330-2. Relator Min. Felix Fischer. T5 - Quinta Turma. DJ 18/06/2007 p. 303)

As turmas do Tribunal Cidadão concordavam neste entendimento, o que pode ser observado no julgado acima proveniente da quinta turma e no julgado a seguir prolato pela sexta turma:

RECURSO ESPECIAL. CRIME CONTRA O MEIO AMBIENTE. OFERECIMENTO DA DENÚNCIA. LEGITIMIDADE PASSIVA. PESSOA JURÍDICA. RESPONSABILIZAÇÃO SIMULTÂNEA DO ENTE MORAL E DA PESSOA FÍSICA. POSSIBILIDADE. RECURSO PROVIDO.

1. Aceita-se a responsabilização penal da pessoa jurídica em crimes ambientais, sob a condição de que seja denunciada em co-autoria com pessoa física, que tenha agido com elemento subjetivo próprio. (Precedentes) 2. Recurso provido para receber a denúncia, nos termos da Súmula $\mathrm{n}^{\circ} 709$, do STF: "Salvo quando nula a decisão de primeiro grau, o acórdão que provê o recurso contra a rejeição da denúncia vale, desde logo, pelo recebimento dela"

(RECURSO ESPECIAL No 800.817 - SC; Rel. Min. Celso Limongi - Des. Convocado do TJSP, Julgamento: 04/02 2010-Órgão Julgador: Sexta Turma).

Ocorre que, não obstante à incontestável compreensão do Superior Tribunal de Justiça sobre o cabimento de denúncia contra entes coletivos pela prática de crimes 
ambientais, havia, no entanto, uma condição de procedibilidade da ação penal, qual seja a imputação simultânea da pessoa física que praticou o ato em nome da empresa, por força da Teoria da Dupla Imputação.

Nesse sentido, o Ministério Público não poderia formular a denúncia apenas contra a pessoa jurídica, devendo, obrigatoriamente, identificar e apontar as pessoas físicas que, atuando em nome e proveito da pessoa jurídica, participaram do evento delituoso, sob pena da denúncia não ser recebida.

Deste modo, a interpretação inicialmente firmada pelo Superior Tribunal foi, por muito tempo, pela possibilidade de responsabilização penal da pessoa jurídica pela prática de crimes contra o meio ambiente, desde que houvesse a punição simultânea da pessoa física que tivesse agido com elemento subjetivo próprio e que tenha atuado em nome da pessoa jurídica, em seu benefício.

Sucede-se que, decorridos alguns anos, o Tribunal Cidadão evoluiu sua interpretação acerca da problemática e passou a afastar essa ressalva. Nos atuais julgados, o Egrégio Tribunal mantêm a acepção de que é possível uma pessoa jurídica figurar no pólo passivo de uma demanda penal, excluindo, porém, a antiga condição de imputação da pessoa física concomitantemente à jurídica.

Nesse caso, não mais seria imperiosa a imputação da pessoa natural que atuou em nome da empresa no momento da prática lesiva contra o meio-ambiente, sendo suficiente a denúncia que pretende punir somente o ente coletivo.

Nesse diapasão, vejamos a mudança de entendimento do Superior Tribunal de Justiça, in verbis:

PENAL E PROCESSUAL PENAL. RECURSO EM MANDADO DE SEGURANÇA. RESPONSABILIDADE PENAL DA PESSOA JURÍDICA POR CRIME AMBIENTAL: DESNECESSIDADE DE DUPLA IMPUTAÇÃO CONCOMITANTE À PESSOA FÍSICA E À PESSOA JURÍDICA.

1. Conforme orientação da $\mathbf{1}^{\mathrm{a}}$ Turma do STF, "O art. $225, \S 3^{\circ}$, da Constituição Federal não condiciona a responsabilização penal da pessoa jurídica por crimes ambientais à simultânea persecução penal da pessoa física em tese responsável no âmbito da empresa. A norma constitucional não impõe a necessária dupla imputação." (RE 548181, Relatora Min. ROSA WEBER, Primeira Turma, julgado em 6/8/2013, acórdão eletrônico DJe-213, divulg. 29/10/2014, public. 30/10/2014).

2. Tem-se, assim, que é possível a responsabilização penal da pessoa jurídica por delitos ambientais independentemente da responsabilização 
concomitante da pessoa física que agia em seu nome. Precedentes desta Corte.

3. A personalidade fictícia atribuída à pessoa jurídica não pode servir de artifício para a prática de condutas espúrias por parte das pessoas naturais responsáveis pela sua condução.

4. Recurso ordinário a que se nega provimento.

(RMS 39173 / BA RECURSO ORDINÁRIO EM MANDADO DE SEGURANÇA 2012/0203137-9. Relator Ministro REYNALDO SOARES DA FONSECA. T5 - QUINTA TURMA. DJe 13/08/2015)

O julgado acima foi proferido pela quinta turma, em contrassenso ao que havia sido prolato pela mesma turma anos antes, conforme citado anteriormente, o que demonstra a mudança de entendimento.

Vale ressaltar que essa mutação na interpretação dos dispositivos que preveem punição penais à pessoas jurídicas se deu a partir de julgado do Supremo Tribunal Federal RE 548.181 - proferido em 2014, o qual teve como relatora a Ministra Rosa Weber, que passou a orientar os posteriores julgados no sentindo de afastar a necessidade de litisconsorte passivo necessário em ações penais ambientais que demande contra pessoas jurídicas.

Isto é, afastou-se como condição de procedibilidade da ação penal a denúncia concomitante da empresa (pessoa jurídica) com o agente (pessoa física) que atuou em nome da empresa.

Para a Ministra Rosa Weber, relatora do paradigma em evidência, não poderia o magistrado substituir o legislador inovando no campo legal, uma vez que nem mesmo a Constituição Federal tampouco a Lei Especial previu tal requisito de condição de procedibilidade.

Perceba, ainda, que o próprio julgado da quinta turma faz menção à este acórdão paradigma prolatado pela primeira turma do Tribunal Cidadão, mas que ainda demorou anos para seguir o entendimento já firmado pelo Supremo Tribunal Federal.

Vejamos ementa do Recurso Extraordinário em comento:

RECURSO EXTRAORDINÁRIO. DIREITO PENAL. CRIME AMBIENTAL. RESPONSABILIDADE PENAL DA PESSOA JURÍDICA. CONDICIONAMENTO DA AÇÃO PENAL À IDENTIFICAÇÃO E À PERSECUÇÃO CONCOMITANTE DA PESSOA FÍSICA QUE NÃO ENCONTRA AMPARO NA CONSTITUIÇÃO DA REPÚBLICA.

1. O art. 225, $\S \mathbf{3}^{\circ}$, da Constituição Federal não condiciona a responsabilização penal da pessoa jurídica por crimes ambientais à simultânea persecução penal da pessoa física em tese responsável no 
âmbito da empresa. A norma constitucional não impõe a necessária dupla imputação.

2. As organizações corporativas complexas da atualidade se caracterizam pela descentralização e distribuição de atribuições e responsabilidades, sendo inerentes, a esta realidade, as dificuldades para imputar o fato ilícito a uma pessoa concreta.

3. Condicionar a aplicação do art. $225, \S^{\circ}$, da Carta Política a uma concreta imputação também a pessoa física implica indevida restrição da norma constitucional, expressa a intenção do constituinte originário não apenas de ampliar o alcance das sanções penais, mas também de evitar a impunidade pelos crimes ambientais frente às imensas dificuldades de individualização dos responsáveis internamente às corporações, além de Supremo Tribunal Federal Documento assinado digitalmente conforme MP $\mathrm{n}^{\circ} 2.200-2 / 2001$ de 24/08/2001, que institui a Infraestrutura de Chaves Públicas Brasileira - ICP-Brasil. O documento pode ser acessado no endereço eletrônico http://www.stf.jus.br/portal/autenticacao/ sob o número 7066890. Supremo Tribunal Federal Inteiro Teor do Acórdão - Página 1 de 64 Ementa e Acórdão RE 548181 / PR reforçar a tutela do bem jurídico ambiental.

4. A identificação dos setores e agentes internos da empresa determinantes da produção do fato ilícito tem relevância e deve ser buscada no caso concreto como forma de esclarecer se esses indivíduos ou órgãos atuaram ou deliberaram no exercício regular de suas atribuições internas à sociedade, e ainda para verificar se a atuação se deu no interesse ou em benefício da entidade coletiva. Tal esclarecimento, relevante para fins de imputar determinado delito à pessoa jurídica, não se confunde, todavia, com subordinar a responsabilização da pessoa jurídica à responsabilização conjunta e cumulativa das pessoas físicas envolvidas. Em não raras oportunidades, as responsabilidades internas pelo fato estarão diluídas ou parcializadas de tal modo que não permitirão a imputação de responsabilidade penal individual.

5. Recurso Extraordinário parcialmente conhecido e, na parte conhecida, provido.

(RECURSO EXTRAORDINÁRIO 548.181 Paraná. Relatora Min. Rosa Weber. Primeira Turma. 06/08/2013)

(Grifo nosso)

Essa mudança de entendimento permitiu evitar impunidades pelos crimes ambientais e, consequentemente, reforçar a tutela do bem jurídico ambiental, visto que havia uma dificuldade de individualização dos responsáveis, o que acabava por deixar impune as empresas comprovadamente danosas ao meio ambiente.

Depois do Superior Tribunal de Justiça ter aderido à mudança de entendimento firmada em primeiro pelo Supremo Tribunal Federal quanto à Teoria da Dupla Imputação, as aplicações nos tribunais mudaram, trazendo um novo molde às jurisprudências que passaram a não mais divergir entre si. 
Podemos observar um cuidado maior com a aplicação da dupla imputação. Para melhor visualização da prática do entendimento, o presente trabalho traz algumas jurisprudências recentes.

Em julgado de 2017 já se via firmado tal entendimento, sem maiores questionamentos:

RECURSO DE APELAÇÃO CRIMINAL - CRIME AMBIENTAL POLUIÇÃO AMBIENTAL EM SUA MODALIDADE CULPOSA [ART. $54, \S 1^{\circ}$, DA LEI N. 9.605/98 - IRRESIGNAÇÃO DEFENSIVA - 1. PRELIMINAR: INÉPCIA DA DENÚNCIA EM RAZÃO DA AUSÊNCIA DE DUPLA IMPUTAÇÃO - DESNECESSIDADE TEORIA SUPERADA - PRECEDENTES DOS TRIBUNAIS SUPERIORES - 2. MÉRITO: NULIDADE DO AUTO DE INFRAÇÃO INOCORRÊNCIA - PRESUNÇÃO DE LEGITIMIDADE DO ATO ADMINISTRATIVO - PRETENDIDA ABSOLVIÇÃO PELA AUSÊNCIA DE PROVAS - IMPOSSIBILIDADE - AUTORIA E MATERIALIDADE DEVIDAMENTE COMPROVADAS - DIMINUIÇÃO DAS PENAS DE MULTA E DA RESTRITIVA DE DIREITOS - POSSIBILIDADE PROPORCIONALIDADE COM A GRAVIDADE DO DELITO E SUAS CIRCUNSTÂNCIAS - RECURSO PARCIALMENTE PROVIDO.

Em consonância com o entendimento dos Tribunais Superiores, o artigo 225, $\S 3^{\circ}$, da Constituição Federal não condiciona a responsabilização penal da pessoa jurídica por crimes ambientais à simultânea persecução penal da pessoa física, estando superada a denominada teoria da dupla imputação. $\mathrm{O}$ auto de infração lavrado pela autoridade ambiental competente goza de presunção de veracidade e legitimidade, constituindo ato administrativo revestido de atributos próprios do Poder Público. Tendo sido comprovado, pelas provas dos autos, notadamente pelos relatórios e depoimentos dos agentes ambientais, que o dano ambiental foi causado pela conduta negligente da empresa ré, a condenação pelo crime ambiental é medida impositiva, não havendo se falar em absolvição por insuficiência de provas. Em obediência aos princípios da proporcionalidade e da individualização da pena, as penas restritivas de direito constantes da Lei de Crimes Ambientais deve seguir os limites máximos da pena privativa de liberdade cominada para a infração praticada. A pena de multa deve ser dosada de acordo com a proporção do dano ambiental, suas circunstâncias e a capacidade econômica do agente.

(TJ-MT - APL: 00000577020168110003 4733/2017, Relator: DES. ORLANDO DE ALMEIDA PERRI, Data de Julgamento: 04/04/2017, PRIMEIRA CÂMARA CRIMINAL, Data de Publicação: 07/04/2017)

Em 2018 seguiu-se pacífica essa linha de entendimento:

RECURSO EM SENTIDO ESTRITO. AÇÃO PENAL PÚBLICA INCONDICIONADA. LEI DE CRIMES AMBIENTAIS. Art. 56, caput, da Lei 9.605/98. DENÚNCIA OFERECIDA EM FACE DA PESSOA JURÍDICA E DE SEU SÓCIO-ADMINISTRADOR. REJEIÇÃO DA DENÚNCIA QUANTO A PESSOA FÍSICA, COM A CONSEQUENTE REJEIÇÃO EM RELAÇÃO A PESSOA JURÍDICA. TEORIA DA 
DUPLA IMPUTAÇÃO. REFORMA. POSSIBILIDADE. SUPERAÇÃO DA NECESSIDADE DE DUPLA IMPUTAÇÃO. RECEBIMENTO DA DENÚNCIA QUANTO A PESSOA JURÍDICA. POSSIBILIDADE. AUSÊNCIA DE VINCULAÇÃO COM A RESPONSABILIDADE PENAL DA PESSOA FÍSICA. MANDADO CONSTITUCIONAL DE CRIMINALIZAÇÃO QUE NÃO IMPÔS RESTRIÇÕES. ART. 225, § $3^{\circ}$, CF. ESPAÇO DE CONFORMAÇÃO DO LEGISLA̧DOR. AUSÊNCIA DE CONDICIONAMENTOS PELO LEGISLADOR ORDINÁRIO. LEI DE CRIMES AMBIENTAIS, ART. $3^{\circ}$. PRECEDENTES DO STF E DO STJ. RECURSO A QUE SE DÁ PROVIMENTO.

1. A tutela do meio ambiente é verdadeiro direito fundamental de titularidade difusa (terceira geração), consistindo a norma constitucional um mandado constitucional de criminalização ao legislador para a instituição de mecanismos de responsabilização penal de infratores da legislação ambiental, sejam pessoas físicas ou jurídicas.

2. A legislação ambiental prevê expressamente regras sobre as sanções penais específicas às pessoas jurídicas, tais como penas de multa, suspensão ou interdição de atividades e até liquidação forçada.

3. Não há, em momento algum, seja no mandado de criminalização contido na $\mathrm{CF}$, seja na norma que lhe regulamentou, qualquer condicionamento à punição das pessoas jurídicas, à caracterização da corresponsabilidade de pessoas físicas.

4. Criar tal vinculação pode impactar a eficácia do princípio constitucional da responsabilidade penal da pessoa jurídica, em crime contra o meio ambiente.

5. Recurso a que se dá provimento, julgando PROCEDENTE o pedido de REFORMA da Decisão judicial recorrida, com o fim de RECEBER a denúncia quanto a pessoa jurídica CARLOS ALEXANDRE RANGEL MAMEDE ME.

(TJ-ES - RSE: 00570350920128080030, Relator: WILLIAN SILVA, Data de Julgamento: 13/12/2017, PRIMEIRA CÂMARA CRIMINAL, Data de Publicação: 12/01/2018)

Por fim, em recente julgado em 2019 confirmou-se ser tese firme a desnecessidade da dupla imputação entre pessoa física e jurídica como condição de procedibilidade da ação penal contra esta última:

CRIME AMBIENTAL. LEI 9.605/1998, ART. 60. MERA CONDUTA. PERIGO ABSTRATO. LICENÇA AMBIENTAL. CONDIÇÕES EXPRESSAS. DESATENDIMENTO. DANO EFETIVO. DESNECESSIDADE. POTENCIALIDADE LESIVA. TIPICIDADE. PESSOA JURÍDICA. DIREITO PÚBLICO. POSSIBILIDADE. DUPLA IMPUTAÇÃO. TEORIA SUPERADA.

1. O crime ambiental descrito no art. 60 da Lei 9.605/1998 é de mera conduta e perigo abstrato, sendo inexigível a prova do dano efetivo.

2. Em conformidade com a jurisprudência do STF, a imputação penal da pessoa jurídica não exige a simultânea imputação da pessoa física por ela responsável, estando superada a Teoria da Dupla Imputação. 
3. Também está amparada pela jurisprudência do STF a possibilidade da responsabilização penal da pessoa jurídica de Direito Público. De fato, ao dispor sobre o tema, o $\S 3^{\circ}$ do art. 225 da Constituição Federal o faz de forma ampla, não distinguindo entre pessoa jurídica de Direito Público e pessoa judídica de Direito Privado.

4. Com efeito, sendo comum a competência para fiscalizar o respeito ao meio ambiente ecologicamente equilibrado e a obrigação de preservá-lo para as gerações presentes e futuras, a culpabilidade dos órgãos do Poder Público que violam as normas de Direito Penal Ambiental pode ser especialmente ponderada.

(TRF-4 - ACR: 50013165820184047121 RS 5001316-58.2018.4.04.7121, Relator: GIOVANI BIGOLIN, Data de Julgamento: 28/02/2019, QUINTA TURMA RECURSAL DO RS)

Feita esta análise, é possível dizer que, atualmente, tanto o Superior Tribunal de Justiça como o Supremo Tribunal Federal desconsideram a necessidade de dupla imputação em crimes ambientais praticados por pessoas jurídicas.

Adverte-se, porém, que a responsabilização criminal das empresas exige que o crime tenha sido cometido pela pessoa jurídica em virtude de decisão de seu representante legal ou órgão colegiado, bem como que a ação tenha ocorrido buscando beneficiar a própria empresa. Esses requisitos são cumulativos e indispensáveis para a responsabilização da entidade abstrata, sendo inquestionáveis condições de procedibilidade da ação, apesar de desnecessária o litisconsorte passivo entre pessoa física e jurídica.

\section{CONCLUSÃO}

Apesar da divergência de opiniões doutrinárias a jurisprudência sempre foi pacífica sobre a possibilidade de responsabilizar penalmente uma entidade jurídica quando da prática de um crime ambiental, apesar de precedentes já superados terem condicionado durante anos a responsabilidade dos entes coletivos à punição concomitante da pessoa física que praticou o ato.

Isso porque, o Poder Judiciário utilizava do argumento da Teoria da Realidade para julgar pela punição das pessoas jurídicas pela prática de condutas lesivas ao meio-ambiente, mas trazia à essa ideia parte da Teoria da Ficção que defende que quem prática o ato em nome da empresa seria uma pessoa natural, motivo pelo qual esta também deveria ser obrigatoriamente responsabilizada. 
Fato este, no entanto, que através de evolução interpretativa observada nos julgados apresentados, não perdurou no ordenamento jurídico, sendo afastada essa condição pelo Supremo Tribunal Federal e, posteriormente, pelo Superior Tribunal de Justiça.

Além disso, conclui-se pelo fato de que o próprio ordenamento jurídico brasileiro previu a responsabilidade penal das pessoas jurídicas diante de condutas criminosas em face do meio ambiente, tendo no aspecto legislativo brasileiro a previsão da responsabilidade penal da pessoa jurídica, tanto no artigo $173 \S 5^{\circ}$, quanto no artigo 225, $\S 3^{\circ}$, da Carta Magna de 1988, os quais estabelecem repressão de delitos cometidos pelas pessoas jurídicas.

Também com a expressa referência na Lei dos Crimes Ambientais (art. $3^{\circ}$, da Lei 9605/98), fica, por fim, superada a polêmica quanto à pertinência da responsabilização penal das pessoas jurídicas, devendo a doutrina, doravante, a se preocupar com a delimitação dos meios adequados para efetivá-la.

Além disso, a efetiva responsabilização das pessoas jurídicas, demonstrado pelos julgados colacionados no capítulo anterior, tem se mostrado meio enérgico e preventivo para evitar reiteradas ações lesivas ao meio ambiente.

\section{REFERÊNCIAS}

BITENCOURT, Cezar Roberto. Manual de direito penal - parte geral. 4. ed. São Paulo: Revista dos Tribunais. 1997.

BRASIL. Constituição da República Federativa do Brasil de 1988.Diário Oficial da República Federativa do Brasil, Brasília, DF - 05 de outubro de 1988.

BRASIL. Lei Ordinária $n^{\circ}$ 9.605, de 12 de fevereiro de 1998.Dispõe sobre as sanções penais e administrativas derivadas de condutas e atividades lesivas ao meio ambiente, e dá outras providencias. Diário Oficial da República Federativa do Brasil, Brasília, DF - 13 de fevereiro de 1998.

BRASIL. Superior Tribunal de Justiça: Agravo Regimental no Recurso em Mandado de Segurança em Mandado de Segurança n ${ }^{\circ} 48085$ - Pará. Relator Ministro Gurgel de Faria. Publicação: 20/11/2015. Órgão Julgador: Quinta Turma.

BRASIL. Superior Tribunal de Justiça: Embargos de Declaração em Recurso Especial $n^{\circ}$ 865.864 - Paraná. Rel. Min. Gilson Dipp. Publicação: 01/02/2012. Órgão Julgador: Quinta 
Turma.

BRASIL. Superior Tribunal de Justiça: Recurso Especial no 800.817- Santa Catarina, Rel. Min. Celso Limongi- Des. Convocado do TJSP, Julgamento: 04/02/2010 - Órgão Julgador: Sexta Turma.

BRASIL. Superior Tribunal de Justiça: Recurso Especial no 889.528 - Santa Catarina. Rel. Felix Fischer. Publicação: 18/06/2007. Órgão Julgador: Quinta Turma.

BRASIL. Superior Tribunal de Justiça: Recurso Ordinário em Mandado de Segurança n 39173 - Bahia. Relator Ministro Reynaldo Soares da Fonseca. Publicação: 13/08/2015. Órgão Julgador: Quinta turma.

BRASIL. Supremo Tribunal Federal: Recurso Extraordinário n 548.181 - Paraná. Relatora Ministra Rosa Weber. 06/08/2013. Órgão Julgador: Primeira Turma.

FERREIRA, Pinto. Comentários à Constituição do Brasil. Vol. 7. São Paulo: Saraiva, 1990.

FREITAS, Vladimir Passos de. Competência nos crimes ambientais - vol 759. São Paulo: Revista dos Tribunais, 1999.

NETO, Nicolao Dino de Castro e Costa; FILHO, Ney de Barros Bello, COSTA, Flavio Dino de Castro e. Crimes e Infrações Administrativas Ambientais. 3 ed. Del Rey, Editora Livraria do Advogado, 2011.

OLIVEIRA, Abel Costa de. A pessoa jurídica no banco dos réus. Campo Grande: Revista Jurídica da FIC-UNAES, 1999.

ROTHENBURG, Walter Claudius. A pessoa jurídica criminosa. Curitiba: Juruá, 1997.

SALES, Sheila Jorge Selim de. Responsabilidade Penal da Pessoa Jurídica: em defesa do princípio da imputação subjetiva. São Paulo: Revista dos Tribunais, 2013.

SAVIGNY, Friedrich Carl von. De la vocación de nuestro siglo para la legislación y la ciencia del derecho. Buenos Aires: Atalaya, 1975.

SHECAIRA, Sérgio Salomão. Responsabilidade penal da pessoa jurídica. São Paulo: Revista dos Tribunais, 1998.

SILVA, José Afonso da. Curso de direito constitucional positivo, 9. ed. São Paulo: Malheiros, 1994.

ZAFFARONI, Eugênio Raul; PIERANGELI, José Henrique. Manual de direito penal brasileiro - parte geral. São Paulo: Revista dos Tribunais, 1997. 